\title{
The Mortality Rate of Pupae and Adult of Fruit Fly Bactrocera cucurbitae Coquillett (Diptera: Tephritidae) Affected by Different Submerging Time and Soil Types under the Laboratory Treatment
}

\author{
Inamullah Khan ${ }^{1 *}$, Amjad Usman ${ }^{2}$ and Rahamdad Khan ${ }^{2}$
}

${ }^{1}$ Nuclear Institute for Food and Agriculture (NIFA) Tarnab, Peshawar, Khyber Pakhtunkhwa, Pakistan; ${ }^{2}$ Department of Entomology, University of Agriculture, Peshawar, Khyber Pakhtunkhwa, Pakistan.

\begin{abstract}
Three separate experiments were carried out to investigate the effect of submerging time under water, pupal age and soil types on mortality and rate of emergence of fruit flies pupae to adult stage. Pupae of Bactrocera cucurbitae Coquillett at different ages by hour i.e., 12, 24, 48, 72 and 96 (hrs) were submerged underwater for ( 1 and $24 \mathrm{hrs}$ ). The rate of pupal emergence to adult stage and mortality was investigated. Results showed that emergence and mortality of $B$. cucurbitae was significantly affected by both submerging time and pupal age. The $12 \mathrm{hrs}$ pupae were more sensitive than $72 \mathrm{hrs}$ pupae, with minimum adult emergence rate and maximum mortality. Results from various submerging times (1, 2, 3 and $4 \mathrm{hrs}$ ) on same age pupae also showed similar trends in pupal's mortality and emergence to adult stage.In further investigation on the effect of four soil texture classes such asclay loam, silt clay loam, sandy loam and pure sand as control, low emergence rate and high mortality was recorded from silt clay loam texture soil as compared to only sand. Hence it is concluded that pupal age, soil texture and under water pupal submergence time has direct effect on the rate of emergence and mortality rate of fruit fly pupae in the soil. Intermittent irrigation of fruit fly host plants standing in clay loam or silt clay loam soil texture may help in controlling the overwintering pupae in the orchards.

Received | September 04, 2019; Accepted | June 08, 2020; Published | August 06, 2020

"Correspondence | Inamullah Khan, Nuclear Institute for Food and Agriculture (NIFA) Tarnab Peshawar, Khyber Pakhtunkhwa, Pakistan; Email: inamullah17@gmail.com

Citation | Khan, I., A. Usman and R. Khan. 2020. The mortality rate of pupae and adult of fruit fly Bactrocera cucurbitae Coquillett (Diptera: Tephritidae) affected by different submerging time and soil types under the laboratory treatment. Sarbad Journal of Agriculture, 36(3): 815-822. DOI | http://dx.doi.org/10.17582/journal.sja/2020/36.3.815.822

Keywords | Bactrocera cucurbitae, Cultural control, Flood irrigation, Mortality, IPM
\end{abstract}

\section{Introduction}

$\mathrm{T}$ he cucurbits such as cucumber, bitter gourd, sponge gourd, bottle gourd, snake gourd, pointed gourd and pumpkins are the major vegetables grown across Pakistan. Among several biotic factors, responsible for the low productivity of cucurbits, the fruit fly B. cucurbitae is most destructive insect pest of fruits and vegetables over the last several decades in many countries of the world including Pakistan. This species of fruit fly is cosmopolitan and distributed in the tropical, subtropical and temperate region of the world (Dhillon et al., 2005).

The fruit fly B. cucurbitae (Coquillet) (Tephritidae: Diptera) lay eggs inside the fruits tissue at 2 to 4 $\mathrm{mm}$ and they prefer to infest soft-skinned young and green fruits. After hatching, the young larvae start feeding inside the fruit tissues. The last instar larvae leave the fruit and fall to the soil for pupation and pupation occurs inside the soil surface at the depth of 0.5 to $15 \mathrm{~cm}$ (Dhillon et al., 2005). The soil texture 
and moisture content play an important role in the movement of larvae and also affect the pupal survival in the soil (Jackson et al., 1998).

Fruit fly has been reported to damage over more than 80 plant species, but crops such as cucumber, the bitter gourd (Momordica charantia), muskmelon (Cucumis melo), snap melon (C. melo var. momordica) and snake gourd (Trichosanthes anguina) are the most preferredhost plants (Ellwood et al. 1999; Dhillon et al.,2005).In Pakistan, the fruit flies cause annual loss to fruit and vegetable over US\$200 million (Stonehouse et al., 1998). The extent of damage is variable ranging from 30 to $100 \%$ depending on season and different cucurbits species (Sapkota et al., 2010). It has also been reported that $B$. cucurbitae infestation vary from 41 to $89 \%$ in Momordica charantia (Rabindranath and Pillai, 1986), in Trichosanthes anguina 90\% , 60 to $87 \%$ in pumpkin fruits (Hollingsworth et al., 1997) and $28.55 \%$ infestation in watermelon (Singh et al., 2000b).

Because of their particular life history, most of the management strategy have focused on adults stage of fruit fly that includes bait traps (McQuate et al., 2005; Vargas et al., 2007), pheromone traps (using cue lures as male attractant) (Leblanc et al., 2011; Vargas et al., 2012; ; Mafra-Neto, 2013; Tan et al., 2014), sterile insect technique (Hendrichs et al., 2002; Dyek et al., 2006) and chemical control (Singh et al., 2000a). However, some attention has been paid to the possibility of fly control by targeting late-instar larvae and pupae in soil type and moisture (E1-Gendy and AbdAllah, 2019; Li et al., 2019) which could be the major lethal factors during the pupal period of fruit fly species. Application of entomopathogenic nematodes (Steinernema feltiae) was found effective to suppress late larval instars of fruit fly in soil. During field tests in Hawaii, drench applications of entomopathogenic nematode ( $S$. feltiae) to the soil increased the mortality of Mediterranean fruit fly larvae by $99.5 \%$ (Lindegren et al., 1990).

The exposure of fruit fly pupae to unfavorable environmental conditions negatively affect pupal survival. (Hennessey and Michael, 1994; Jackson et al., 1998). Soil texture and moisture content plays an important role in provision of nutrients to the plants but it may negatively affect the hibernating fruit flies pupae in such soils. Research on the influence of soil texture and moisture content on the survival of fruit fly pupae hibernating underneath the host plant may provide useful clues in their control. Knowledge on the effect of host plant irrigation, timing, soil moisture content and field saturation is necessary for devising new strategies useful in the cultural control of fruit flies. In addition, the effect of flood irrigation under natural conditions may also play important role on the survival fruit fly species. Keeping in view the above hypothesis, the present study was conducted to investigate the effect of different types of soils and water submerging timeson the different and uniform age $B$. cucurbitae pupae as a cultural control measure.

\section{Materials and Methods}

\section{Establishment of fruit flies culture}

The current research work was conducted under laboratory condition at the Nuclear Institute for Food and Agriculture (NIFA), Tarnab Peshawar, Pakistan. Fruit fly culture was established under laboratory condition $26 \pm 2^{\circ} \mathrm{C}$ and $70 \%$ R.H. The fruit fly infested fruits and vegetables were collected from the field and placedon pupal substrates having saw dust in the bottom for fruit fly pupation. After four to five days, the saw dust of the pupal substrate was sieved and pupae were collected. The collected pupae were placed in fruit fly rearing cage for adult emergence. After emergence, adults inside the cage were provided with artificial adult diet. The adult started mating after 10-12 days. Vegetable (as host) was placed inside the rearing cage for female to lay eggs. After two or three days, the host in which the eggs were laid inside the cage was transferred to the pupal substrate for pupation. The same methodology was repeated to maintain the fruit fly stock culture for further experiments.

\section{Effect of different submerging time on B.cucurbitae pupae of different ages}

Pupal substrate was prepared from clay loam soil. The pupal substrate was filled in plastic PEPSI bottles which served as pupal cage. Both end of the bottles was cut off at the tapering position. Lower end of the cage was covered with muslin cloth. One third of the pupal cages was filled with pupal substrate. Fifteen pupae of the required age $(12,24,48,72$, $96 \mathrm{hrs}$.) were obtained from the stock culture and placed in each cage at the depth of $15 \mathrm{~cm}$. The pupal age and submerging time served as treatment (five treatments) and three replicates per treatment. The upper opening of the cage was covered with muslin 
cloth and tightened with rubber band. Plastic tubs were filled with tap water and pupal cages were submerged in water up to the marked pupal position in the cage for various durations $(0,1,24 \mathrm{hrs}$.). After submerging for the required period, the pupae cages were taken out of the water and waited for pupae to emerge in the cage. Data on the adult emergence was recorded by counting the number of adults emerged in each cage. All emerging adults of B. cucurbitae were further transferred to adult cages and provided with $10 \%$ sugar and honey as artificial diet. Their mortality and longevity was recorded up to 3 months.

\section{Effect of submerging time on uniform (24 hrs) old pupae of B. cucurbitae}

Fifteen pupae of uniform ( $24 \mathrm{hr}$ ) age were obtained from the stock culture and placed in pupal cage at the depth of $15 \mathrm{~cm}$. as in experiment above. The upper opening of the cage was covered with muslin cloth and tightened with rubber band. Each cage with known number of same age pupae was submerged in water tubs for $0,1,2,3$ and $4 \mathrm{hr}$ duration. Pupae in the control were not submerged. After submerging for the required duration, the pupae cages were taken out from their respective tubs and placed in laboratory. Data on the adult emergence was recorded from each cage as in the first experiment. All emerging adults of B. cucurbitae were transferred to adult cages and provided with $10 \%$ sugar and honey as artificial diet. The adult's mortality and longevity was recorded up to 3 months on regular basis.

\section{Effect of various soil types on uniform (24 hrs) old pupae of B. cucurbitae}

Separate experiment was carried out to ascertain the effect of various soil types on emergence of uniform $24 \mathrm{hrs}$ old pupae of $B$. cucurbitae under laboratory conditions at $26 \pm 2{ }^{\circ} \mathrm{C}$ and $70 \% \mathrm{RH}$. Four different types of pupal cages as in experiment 1 and 2 were prepared with various texture pupal substrates from soils i.e clay, silt clay loam, sandy loam and pure sand as control. Fifteen uniform age $(24 \mathrm{hrs})$ old pupae of $B$. cucurbitae were obtained from the stock culture maintained in the laboratory and placed at a depth of $15 \mathrm{~cm}$. in each cage with different soil textures. The upper end of the cage was covered with muslin cloth and tightened with rubber band. The pupae remain in the soil till adult emergence. The data on adult emergence and mortality was recorded for up to 2 months. The experiment comprised of 4 soil textures as treatments 3 replications of each treatment.

\section{Results and Discussion}

Effect of different submerging time on B.cucurbitae pupae of different ages

Results revealed that the percent emergence of B.cucurbitaepupae to adult wassignificantly affected by both submerging time and pupal age (Table 1 ). It is clear from the data that all the tested pupal age showed similar adult emergence of $93 \%$ with 0 submerging time. However, significant differences were found in mean percent adult emergence with respect to submerging time. The adult emergence was maximum (43.88\%) at 1 hour submerging and minimum (29.39\%) when the pupae were submerged for $24 \mathrm{hrs}$. The adult emergence was lowest (31.10\%) for $12 \mathrm{hrs}$ old pupae at $1 \mathrm{hr}$ submerging time followed by $32.90,37.66,55.50$ and $62.20 \%$ adult emergence for $24,48,72$, and $96 \mathrm{hrs}$ old pupae respectively. Significant differences were found in mean percent pupal emergence to adult stage with respect to pupal age. The adult emergence increased with respect to increase in pupal age. Minimum number (6.66\%) of adults emerged from $12 \mathrm{hrs}$ old pupae when submerged for $14 \mathrm{hrs}$ followed by $24 \mathrm{hrs}$ old pupae (7.0\%), 48 hrs old pupae (24.46\%), 72 hrs old pupae (48.90\%) and 96 hrs old pupae (59.96\%). The adult emergence with respect to submerging time was lowest (43.68\%) for $12 \mathrm{hrs}$ old pupae while highest (71.82\%) for 96 hrs old pupae. The present findings are in agreement with Pablo et al. (2008) who reported that young pupae were more susceptible than old pupae when immerse in rain water for different submerging time. EsKafi and Fernandez (1990) reported that when moisture content reached to the saturated point, the adult emergence of $C$. capitata dropped drastically. According to Hulthen and Clark (2006), the most significant factor affecting pupae was extremes in soil moisture. $85 \%$ pupal mortality occurred at $0 \%$ soil moisture and 30\% pupal mortality occurred at 100\% soil moisture. The good rate of pupal survival in soils with low moisture is most likely an adaptation to semi-desert climate in the Mexican northeast where this species originated. Similar results have been reported by Bressannto (2001) for pupal mortality due to desiccation in A. obliqua, (Hou et al., 2006) in C. capitata and (Jackson et al. 1998) in B. dorsalis. In addition, Fitt (1981) reported that survival of Dacus opiliae were drastically reduced in soils with moisture content below $10 \%$.

In the present work, adult's emergence from soil with 
more submerging times threatened pupal survival. When moisture content retained for long, adult emergence dropped drastically, perhaps due to a lack of oxygen, as pointed out by Eskafi and Fernandez (1990) for C. capitata. The survival of the pupal stage of $B$. dorsalis was inhibited when soil moisture reached the field capacity (Hou et al., 2006). In our research, under normal condition with 0 submerging level, no effect on the emergence rate was recorded.

Table 1: Percent of the meantime of adult emergence of B. cucurbitae affected by submerging time and pupal age.

\begin{tabular}{|c|c|c|c|c|}
\hline \multirow{2}{*}{$\begin{array}{l}\text { Pupal age } \\
\text { (hrs) }\end{array}$} & \multicolumn{3}{|c|}{ Submerging time (hrs) } & \multirow{2}{*}{$\begin{array}{l}\text { Percent of the } \\
\text { meantime of } \\
\text { adult emergence }\end{array}$} \\
\hline & 0 & 1 & 24 & \\
\hline 12 & $93.30 \mathrm{a}$ & $31.10 \mathrm{de}$ & $6.66 \mathrm{f}$ & $43.68 \mathrm{~d}$ \\
\hline 24 & $93.30 \mathrm{a}$ & $32.90 \mathrm{e}$ & $7.00 \mathrm{f}$ & $44.60 \mathrm{~d}$ \\
\hline 48 & $93.30 \mathrm{a}$ & $37.66 \mathrm{~d}$ & $24.46 \mathrm{e}$ & $51.81 \mathrm{c}$ \\
\hline 72 & $93.30 \mathrm{a}$ & $55.56 \mathrm{~b}$ & $48.90 \mathrm{bc}$ & $65.82 \mathrm{~b}$ \\
\hline 96 & $93.30 \mathrm{a}$ & $62.20 \mathrm{~b}$ & $59.96 \mathrm{~b}$ & $71.82 \mathrm{a}$ \\
\hline $\begin{array}{l}\text { Mean per- } \\
\text { cent adult } \\
\text { emergence }\end{array}$ & $93.30 \mathrm{a}$ & $43.88 \mathrm{~b}$ & $29.39 c$ & \\
\hline
\end{tabular}

Means followed by different letters in respective column are significantly different at 5\% level of significance followed by LSD Test; LSD (0.05) for submerging time: 3.917; LSD (0.05) for pupal age: 5.05; LSD (0.05) for submerging time x pupal age: 8.75

Post emergence adult's mortality of B. cucurbitae affected by submerging time and pupal age

Results given in Table 2 showed that post emergence percent adult mortality of B. cucurbitae was significantly affected by both submerging time and pupal age. With the progression in pupal age, post emergence adult's mortality decreased. Similarly, with the increase in submerging time, post emerged adult mortality increased. Data indicates that non-significant difference in post emerged adult mortality was found with 0 submerging time. The post emergence adult mortality was minimum (1.9\%) at 0 submerging time, followed by $1 \mathrm{hr}$ submerging and maximum at (3.2\%) for 24 hrs. submergence time. It indicates that post emergence adult mortality is also affected with pupal age and submerging time. The post emergence adult mortality was found to be maximum (3.0\%) for 12 hrs old pupae when submerged for $1 \mathrm{hr}$ followed by $24 \mathrm{hrs}$ old pupae (2.\%), 48 hrs old pupae (2.3\%), 72 hrs old pupae (2.0\%) and 96 hrs old pupae (2.0\%). The post emergence adult mortality was highest (3.7\%) for 12 hrs old pupae $3.33 \%$ for 24 hrs submerging time followed by $2.66 \%$ for $48 \mathrm{hrs}$ old pupae respectively.

Table 2: Post emergence adult's mortality (\%) of $B$. cucurbitae affected by pupal age and water submerging time.

\begin{tabular}{|c|c|c|c|c|}
\hline \multirow[t]{2}{*}{ Pupal age (hrs) } & \multicolumn{3}{|c|}{ Submerging time (hrs) } & \multirow{2}{*}{$\begin{array}{l}\text { Means percent } \\
\text { adult mortality }\end{array}$} \\
\hline & 0 & 1 & 24 & \\
\hline 12 & $2.33 \mathrm{~b}-\mathrm{d}$ & $3.00 \mathrm{abc}$ & $3.66 \mathrm{a}$ & $3.00 \mathrm{a}$ \\
\hline 24 & $2.00 \mathrm{~cd}$ & $3.33 \mathrm{ab}$ & $3.33 \mathrm{ab}$ & $2.88 \mathrm{ab}$ \\
\hline 48 & $2.00 \mathrm{~cd}$ & $2.33 \mathrm{~b}-\mathrm{d}$ & $2.66 \mathrm{a}-\mathrm{d}$ & $2.33 \mathrm{bc}$ \\
\hline 72 & $1.66 \mathrm{~d}$ & $2.00 \mathrm{~cd}$ & $3.33 \mathrm{ab}$ & $2.33 \mathrm{bc}$ \\
\hline 96 & $1.66 \mathrm{~d}$ & $2.00 \mathrm{~cd}$ & $3.00 \mathrm{a}-\mathrm{c}$ & $2.22 \mathrm{c}$ \\
\hline $\begin{array}{l}\text { Mean percent } \\
\text { adult mortality }\end{array}$ & $1.93 \mathrm{c}$ & $2.53 \mathrm{~b}$ & $3.20 \mathrm{a}$ & \\
\hline
\end{tabular}

Means followed by different letters in respective column are significantly different at 5\% level of significance followed by LSD test; LSD (0.05) for submerging time: 0.48; LSD (0.05) for pupal age: 0.62; LSD (0.05) for submerging time x pupal age: 1.08

Significant differences were also found in mean percent adult emergence with respect to pupal age and submerging time. The younger pupae were found to be more susceptible with maximum mortality rate as compared to the old pupae. Similarly, the adult mortality with respect to submerging time was lowest $2.2 \%$ for older (96 hrs) pupae while highest 3.0\% for youngest (12 hrs) pupae.

\section{Effect of different submerging time on uniform age (24 hrs) old pupae of B. cucurbitae}

Results presented in Table 3 revealed that $B$. cucurbitae adult emergence was significantly affected by submerging time. The adult emergence was highest (91.1\%) in control while lowest (26.7\%) for pupae submerged for $4 \mathrm{hrs}$. However, adult emergence calculated for the pupae submerged for 1,2,3 and $4 \mathrm{hrs}$ were on-significant from each other but significantly lower than the control.

Results regarding post emergence adult mortality, showed that adult mortality was significantly high (4.0\%) for pupae submerged for $4 \mathrm{hr}$ and low (1.7\%) in control. Similarly, adult emergence from pupae submerged for 1, 2 and $3 \mathrm{hr}$, and $4 \mathrm{hrs}$ was statistically non-significant from each other but significantly lower than control (no submerging). It is clear that pupal submerging time is directly proportional to the post emergence adult mortality of fruit fly. As the submerging time increased the post emergence adult mortality also increased and vice versa. Almost similar 
results were reported by (Liu, 1983) with respect to rainfall and soil moisture content on the development and survival of immature $B$. dorsalis fruit fly. Their populations were considerably depressed and after being subjected to prolong submerging in water and heavy rains for several days.

Table 3: Post emergence adult mortality (\%) and emergence of uniform age (24 hrs old) B. cucurbitae pupae affected by submerging time.

$\begin{array}{lll}\begin{array}{l}\text { Submerging time } \\ \text { (hrs) }\end{array} & \begin{array}{l}\text { Adult emer- } \\ \text { gence (\%) }\end{array} & \begin{array}{l}\text { Post emergence adult } \\ \text { mortality (\%) }\end{array} \\ 1 & 33.32 \mathrm{~b} & 2.33 \mathrm{bc} \\ 2 & 35.53 \mathrm{~b} & 2.66 \mathrm{~b} \\ 3 & 35.54 \mathrm{~b} & 2.66 \mathrm{~b} \\ 4 & 26.66 \mathrm{~b} & 4.00 \mathrm{a} \\ \text { No submerging } & 91.09 \mathrm{a} & 1.66 \mathrm{c} \\ \text { (control) } & & 0.93 \\ \text { LSD (0.05) } & 14.35 & \\ \text { Means followed by different letters in respective column are } \\ \text { significantly different at 5\% level of significance followed by LSD test. }\end{array}$

Effect of various soil types on uniform age ( 24 hrs old) pupae of B. cucurbitae

$B$. cucurbitae percent adult emergence was significantly affected by the soil texture (Table 4). The results from tested soil types showed highest adult emergence (88.9\%) in control (pure sand) while the lowest adult emergence (11.1\%) was recorded in silt clay loam. The adult's emergence in clay loam and silt clay loam was $17.8 \%$ and $11.1 \%$ respectively. The adult's emergence in sandy loam soil was significantly higher than the adult's emergence in silt clay loam.

Table 4: Effect of soil type on adult emergence and post emergence adult's mortality of B. cucurbitae.

$\begin{array}{lll}\text { Soil type } & \begin{array}{l}\text { Adult emergence } \\ \text { (\%) }\end{array} & \begin{array}{l}\text { Adult mortal- } \\ \text { ity (\%) }\end{array} \\ \text { Clay loam } & 17.77 \mathrm{bc} & 5.88 \mathrm{~b} \\ \text { Silt clay loam } & 11.10 \mathrm{c} & 11.93 \mathrm{a} \\ \text { Sandy loam } & 24.43 \mathrm{~b} & 5.44 \mathrm{~b} \\ \text { Control (pure sand) } & 88.86 \mathrm{a} & 3.15 \mathrm{c} \\ \text { LSD }(0.05) & 11.43 & 0.50\end{array}$

Means followed by different letters in respective column are significantly different at $5 \%$ level of significance followed by LSD test.

Post emergence adult mortality was also significantly affected by the soil types (Table 4). Highest adult mortality $(3.6 \%)$ was observed in the pure sand (control) which was significantly higher than the remaining tested soils types. The lowest fruit fly post emergence adult mortality was observed in the silt clay loam soil i.e. (11.9\%). The post emergence adult's mortality in clay loam and sandy loam was non-significant from each other but significantly lower than silt clay loam. Bento et al. (2010) also investigated that the number of emerged D. longicaudata adults was three times higher in sandy loam and lower in a heavy clay soil. The silt clay loam texture reduces the emergence rate of $C$. capitata but the sandy loam soil favors the pupation Ahmad et al. (2007). Similarly, the pupation depth to which the larva burrows into the soil is also affected by soil texture, moisture, compaction and temperature Dimou et al., 2003.

\section{Conclusions and Recommendations}

The present study warrants for fruit fly cultural control practices and indicates that the fruit fly papal emergence and post adult survival is directly affected by the pupal age, submerging time and soil texture classes. Field populations of fruit fly may be depressed considerably if their pupae are subjected to under water submersion from intermittent irrigation or rains for several days. This effect may be more prominent if the standing crop is grown in a clay loam or silt clay loam type soils.

\section{Novelty Statement}

This research will provide baseline information about fruit flies, which can further be used to develop management strategy for fruit fly in natural field conditions.

\section{Author's Contribution}

IK conceived the idea, wrote the manuscript, $\mathrm{Co}_{-}$ supervise the student and critically reviewed the article. RK conducted the experiments, collected data. AU conducted the statistical analysis, wrote the manuscript and supervised the student.

\section{Conflict of interest}

The authors have declared no competing interest.

\section{References}

Ahmad, A.D., N. Soltani, A. Kellouche and F. 
Mazouzi. 2007. Effects of the soil texture and the burying depth of the larvae on some biological parameters of Ceratitis capitata (Diptera: Trypetidae). Afr. J. Agric. Res. 2(3): 105-111.

Alyokhin, A.V., C. Mille, R.H. Messing and J.J. Duan. 2001. Selection of pupation habitats by oriental fruit fly larvae in the laboratory. J. Insect. Behav. 14(1): 57-67. https://doi. org/10.1023/A:1007849629409

Bento, F.D.M.M., R.N. Marques, M.L.Z. Costa, J.M.M. Walder, A.P. Silva and J.R.P. Parra. 2010. Pupal development of Ceratitis capitata (Diptera: Tephritidae) and Diachasmimorpha Longicaudata (Hymenoptera: Braconidae) at different moisture values in four soil types. Envirvon. Entomol. 39(4): 1315-1322. https:// doi.org/10.1603/EN08088

Bressan, N.S., 2001. Emergence and pupal mortality factors of Anastrepha obliqua (Macq.) (Diptera: Tephritidae) along the fruiting season of the host Spondias dulcis L. Neotropical Entomol. 30: 207-215. https://doi.org/10.1590/S1519566X2001000200002

Cherry, R.H., 1984. Flooding to control the grub Ligyrus subtropicus (Coleoptera: Scarabaeidae) in Florida sugarcane. J. Econ. Entomol. 77(1): 254-257. https://doi. org/10.1093/jee/77.1.254

Dhillon, M.K., R. Singh, J.S. Naresh and H.C. Sharma. 2005. The melon fruit fly, Bactrocera cucurbitae: A review of its biology and management. J. Insect. Sci. 5: 1-16. https://doi. org/10.1093/jis/5.1.40

Dimou, I., C. Koutsikopoulos and A.P. Economopoulos. 2003. Depth of Pupation of the wild Olive fruit fly, Bactrocera oleae (Dipt., Tephritidae), as affected by soil abiotic factors. J. Appl. Entomol. 127(1): 12-17. https://doi. org/10.1046/j.1439-0418.2003.00686.x

Dyck, V.A., Hendrichs, J. and Robinson, A.S., 2006. Sterile insect technique: principles and practice in area-wide integrated pest management Springer. https://doi.org/10.1007/1-40204051-2

Ellwood, A.J., A. Chinajariyawong, R.A.I. Drew, E.L. Hamacek, D.L. Hancock, C. Hengsawad, J.C. Jinapin, M. Jirasurat, C.K. Krong, S. Kritsaneepaiboon, C.T.S. Leong and S. Vijaysegaran. 1999. Host plant records for fruit flies (Diptera: Tephritidae) in South-East Asia.
Raffies Bull. Zool. 7: 1-92.

El-Gendy, I.R. and A.M. AbdAllah. 2019. Effect of soil type and soil water content levels on pupal mortality of the peach fruit fly Bactrocera zonata (Saunders) (Diptera: Tephritidae). Int. J. Pest Manage. 65: 154-160. https://doi.org/10.1 080/09670874.2018.1485988

Eskafi, M., F. Fernandez and Alejandra. 1990. Larval-pupal mortality of Mediterranean fruit fly (Diptera: Tephritidae) from Interaction of Soil, Moisture, and Temperature. Environ. Entomol. 19(6):1666-1670. https://doi. org/10.1093/ee/19.6.1666

Fitt, G.P., 1981. Pupal survival of two northern Asutralian Tephritid species and its relationship to soil conditions. J. Aust. Entomol. Soc. 20: 139-144. https://doi. $\mathrm{org} / 10.1111 / \mathrm{j} .1440-6055.1981 . t b 01016 . x$

Hendrichs, J., A.S. Robinson, J.P. Carol and W. Enkerlin. 2002. Medfly area wide sterile insect technique programmes for prevention, suppression on eradication: the importance of mating behaviour studies. Florida Entomol. 85: 1-13. https://doi.org/10.1653/00154040(2002)085[0001:MASITP]2.0.CO;2

Hennessey, A. and K. Michael. 1994. Depth of pupation of Caribbean fruit fly (Diptera: Tephritidae) in soils in the laboratory. Environ. Entomol. 23(5): 119-1123. https://doi. org/10.1093/ee/23.5.1119

Hollingsworth, R.M. Vagalo and F. Tsatsia. 1997. Biology of melon fly, with special reference to the Solomon Islands. In: Allwood AJ and Drew RAI editors. Management of fruit flies in the Pacific. Proc. Austr. Count. Indust. Agric. Res., 76: 140-144.

Hou, B., Q. Xie and R. Zhang. 2006. Depth of pupation and survival of the Oriental fruit fly, Bactrocera dorsalis (Diptera: Tephritidae) pupae at selected soil moistures. Appl. Entomol. Zool. 41(3): 515-520. https://doi.org/10.1303/ aez.2006.515

Hulthen, A.D. and A.R. Clarke. 2006. The influence of soil type and moisture on pupal survival of Bactrocera Tryoni (Froggatt) (Diptera: Tephritidae). Aust. J. Entomol. 45(1): 16-19. https://doi.org/10.1111/j.14406055.2006.00518.x

Jackson, C.G., J.P. Long and L.M. Klungness. 1998. Depth of pupation in four species of fruit flies (Diptera: Tephritidae) in sand with 
and without moisture. J. Econ. Entomol. 91(1): 138-142. https://doi.org/10.1093/jee/91.1.138

Jacques, R., R. Robert and R.E. Stinner. 1981. Effect of soil moisture and texture on survival and development of eggs and first instar grubs. Environ. Entomol. 10(5): 654-660. https://doi. org/10.1093/ee/10.5.654

Leblanc,L.,R.I.Vargas,B.MacKey,R.Putoa andJ.C. Piñero. 2011. Evaluation of cue-lure and methyl eugenol solid lure and insecticide dispensers for fruit fly (Diptera: Tephritidae) monitoring and control in Tahiti. Fla. Entomol., 94: 510-517. https://doi.org/10.1653/024.094.0315

Li Z., C. Chambi, T. Du, C. Huang, F. Wang, G. Zhang, C. Li and M.J. Kayeke. 2019. Effects of Water Immersion and Soil Moisture Content on Larval and Pupal Survival of Bactrocera minax (Diptera: Tephritidae). Insects. 10: 138. https://doi.org/10.3390/insects10050138

Lindegren, J.E., T.T. Wong and D.O. McInnis. 1990. Response of Mediterranean fruit fly (Diptera: Tephritidae) to the entomogenous nematode Steinernema feltiae in field tests in Hawaii. Environ. Entomol. 19: 383-386. https://doi.org/10.1093/ee/19.2.383

Liu, Y.C., 1983. Populations studies on the oriental fruit fly Dacus dorsalis Hendel in Central Taiwan. In: R. Cavalloro [ed.], Proc. CEC/IOBC Intl. Symp. on Fruit Flies of Economic Importance, A. A. Balkema, Rotterdam. pp. 62-67.

Maelzer, D.A., 1961. The effect of temperature and moisture on the Immature Stages of Aphodius tasmaniae Hope (Scarabaeidae) in the lower South-east of South Australia. Aust. J. Zool. 9(2): 173 - 202. https://doi.org/10.1071/ ZO9610173

Mafra-Neto, A., M. Frédérique, C.J. Fettig, A.S. Munson, T.M. Perring, L.L. Stelinski, L. Stoltman, L.E. Mafra, R. Borges and R.I. Vargas. 2013. Manipulation of insect behavior with Specialized Pheromone and Lure Application Technology (SPLAT $\left.{ }^{\circledR}\right)$. Nat. Prod. Pest Manage. Washington, D.C. ACS Publ.3158. Chapter 4: 31-58. https://doi.org/10.1021/ bk-2013-1141.ch004

McQuate, G.T., S.L. Peck, P.G. Barr and C.D. Sylva. 2005. Comparative evaluation of spinosad and phloxine $\mathrm{B}$ as toxicants in protein baits for suppression of three fruit fly (Diptera: Tephritidae) species. J. Econ. Entomol. 98: 1170-1178. https://doi.org/10.1603/0022-
0493-98.4.1170

Montoya, P., S. Floras and J. Toledo. 2008. Effect of rainfall and soil moisture on survival of adults and immature stages of Anastrepha ludens and Oblique (Diptera: Tephritidae) under semi-field conditions. Fla. Entomol. 91(4): 644-650.

Muteroa, C.M., H. Blankb., F. Konradsenb and W.V.D. Hoekb. 2000. Water management for controlling the breeding of Anopheles mosquitoes in rice irrigation schemes in Kenya. Acta Trop. 76(3): 253-263. https://doi. org/10.1016/S0001-706X(00)00109-1

Pablo, M., S. Flores and J. Toledo. 2008. Effect of rainfall and soil moisture on survival of adults and immature stages of Anastrepha ludens and A. obliqua (Diptera: Tephritidae) under semifield conditions. Fla. Entomol. 91(4): 512-516.

Rabindranath, K. and K.S. Pillai. 1986. Control of fruit fly of bitter gourd using synthetic pyrethroids. Entomol. 11: 269-272.

Renkema, J.M., G.C. Cutler, D.H. Lynch, K. MacKenzie and S.J. Walde. 2011. Mulch type and moisture level affect pupation depth of Rhagoletis mendax Curran (Diptera: Tephritidae) in the laboratory. J. Pest Sci. 84: 281-287. https://doi.org/10.1007/s10340011-0365-2

Sapkota, R., K.C. Dahal and R.B. Thapa. 2010. Damage assessment and management of cucurbit fruit files in spring-summer squash. J. Ento. Nematol. 2(1): 7-12.

Serit, M. and K.H. Tan. 1990. Immature life table of Dacus dorsalis Hendel in a village ecosystem, Penang Island, Malaysia. Trop. Pest. Manage. 36: 305-309. https://doi. org/10.1080/09670879009371493

Siddiqui, Q. and M. Ashraf. 2002. Significance of moisture percentage and depth levels of pupation substrate in the quality production of Bactrocera zonata (Diptera: Tephritidae). Pak. J. Biol. Sci. 5(12): 1311-1312. https://doi. org/10.3923/pjbs.2002.1311.1312

Singh, S., R.N. Gupta, B.A. Awasthi, R.A. Verma and S. Singh. 2000a. Effective control of ber fruit fly Carpomya Vesuviana by insecticidal schedule. Indian J. Entomol. 62(2): 171-174.

Singh, S.V., A.Mishra, R.S. Bisan, Y.P.Malik and A. Mishra. 2000b. Host preference of red pumpkin beetle, Aulacophora foveicollis and melon fruit fly, Dacus cucurbitae. Indian J. Entomol. 62: 242246. 
Stark, J.D., R.I. Vargas and R.K. Thalman. 1990. Azadirachtin: effects on metamorphosis, longevity, and reproduction of three tephritid fruit fly species (Diptera: Tephritidae). J. Econ. Entomol. 83: 2168-2174. https://doi. org/10.1093/jee/83.6.2168

Stonehouse J.M., Mumford J.D. and Mustafa, G., 1998. Economic losses to tephritid fruit flies (Diptera: Tephritidae) in Pakistan. Crop Prot. 17: 159-164. https://doi.org/10.1016/S02612194(97)00091-4

Tan, K.H., R. Nishida, E.B. Jang and T.E. Shelly. 2014. Pheromones, male lures, and trapping of tephritid fruit flies, Trapping and the detection, control, and regulation of Tephritid fruit flies, Springer. pp. 15-74. https://doi. org/10.1007/978-94-017-9193-9_2

Turpin, F.T. and D.C. Peters. 1971. Survival of southern and western corn root worm larvae in relation to soil texture. J. Econ. Ento. 64(6): 1448-1451. https://doi.org/10.1093/ jee/64.6.1448
Vargas R.I., L. Leblanc, R. Putoa and A. Eitam. 2007. Impact of introduction of Bactrocera dorsalis (Diptera: Tephritidae) and classical biological control releases of Fopius arisanus (Hymenoptera: Braconidae) on economically important fruit flies in French Polynesia. J. Econ. Entomol. 100: 670-679. https://doi. org/10.1093/jee/100.3.670

Vargas R.I., S.K. Souder, B. MacKey, P. Cook, J.G. Morse, J.D. Stark. 2012. Field trials of solid triple lure (trimedlure, methyl eugenol, raspberry ketone, and DDVP) dispensers for detection and male annihilation of Ceratitis capitata,Bactrocera dorsalis, and Bactrocera cucurbitae (Diptera: Tephritidae) in Hawaii. J. Econ. Entomol. 105: 1557-1565. https://doi. org/10.1603/EC12122

Yokoyama, V.V. and G.T. Miller. 2007. Olive fruit fly biology and cultural control practices in California. Integr. Projection Olive Crops Bull. 30(9): 263-269. 